\title{
Reflections on retirement: Is that the way to say goodbye?
}

\author{
Cite as: CMAJ 2019 March 18;191:E315-6. doi: 10.1503/cmaj.181136
}

CMAJ Podcasts: audio reading at https://soundcloud.com/cmajpodcasts/181136-enc

\begin{abstract}
first met Corinne at an adolescent clinic back in 1983. Sixteen years old, she was requesting a pregnancy test because of unprotected sex while drunk. She drank daily. Working together, we realized that alcohol was the smokescreen that hid her anguish. At university, she suffered a psychotic episode and was diagnosed with bipolar disorder. Her 20 s and 30 s were spent ricocheting from one institution to another. I managed to connect her to a community psychiatrist who had the compassion to open his door to someone with her challenges. Despite at least 20 hospital admissions over 35 years, she has been a loving single mom to two children and won a coveted scholarship for part-time university students. She has been dry for 20 years.
\end{abstract}

She is now 51. We have seen each other an average of twice a month over the last 35 years.

How to tell her I am retiring from practice?

Though some jurisdictions are publishing retirement guides, there is no best practice as to how to do this with elegance and grace. ${ }^{1}$ I am in the first wave of baby boomers, joining a corps of older physicians contemplating leaving practice. It is projected that, by $2026,20 \%$ of physicians will be over $65 .{ }^{2}$ Although there is a trend for physicians to retire later, by age 70 most physicians are no longer in practice. ${ }^{3,4}$

Looking back, I realize that family medicine offered me a rich tapestry of human experience and the time to grow relationships. My practice became a mirror of

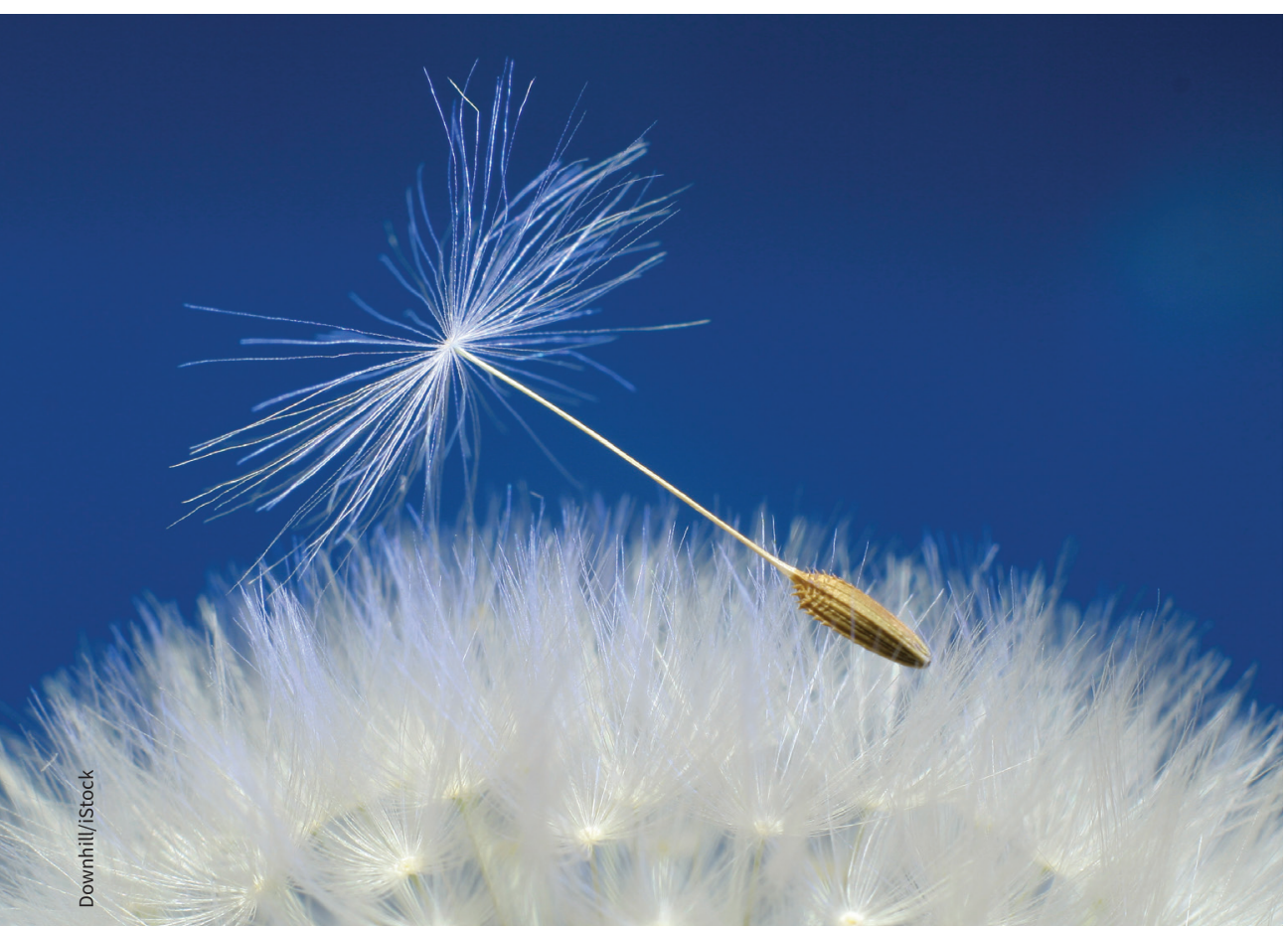

primary care reform, evolving from a paperbased community office to part of a digitally enabled interprofessional team. Thankfully neither illness nor diminishing skill forced my retirement. Rather, leading a family health team sparked my interest in broader health system reform. A growing restlessness compelled me to consider facilitating change at the population level rather than continue serving one patient at a time.

Before hanging up my laboratory coat, my first commitment was to leave the practice in capable hands, ideally with a doctor my patients could get to know and like. In my favour was a well-situated office close to teaching hospitals, supported by capitated payment, an interprofessional care team and electronic medical records. I count my blessings. For some of my dedicated colleagues, this may not be the case (useful advice is available from HealthForceOntario ${ }^{5}$ or provincial medical associations).

I recruited a competent physician, assuming that her values, similar to mine, and her life experience would allow her to minister effectively to an older population. She and a kind former resident did locums for two years before my departure, providing a reassuring bridge for many of my patients.

Does this mean the transition will be without a hitch? It takes time to build sustaining relationships. When patients say to me, "But she's not you," I reply, "I wasn't me either when I started." The patients will "hatch" these young doctors to embody patient-centred care. And my colleagues will impart to patients their own principles and boundaries as family physicians.

Another goal included modelling my management of complex aging patients and running an efficient practice. The new recruits reviewed administrative 
expectations and signed memoranda of understanding. Still I anticipated that they would embark on a new chapter in running the practice. This was another necessary milestone in letting go. I realized that, in time, the office will not look like the one I built over 35 years, and it is no longer my ship to steer.

To begin my farewell to patients, I sent a letter six months before my stated departure. The following themes were covered: my decision to leave practice, the value of staying with our family health team and the introduction of my successors, colleagues from whom they should expect a similar high standard of care.

Responses to my retirement reflected the spectrum of expectations patients bring to their care. Many were predictably sad and fearful about losing a physician who had come to know and advocate for them. Several were so upset they could not get through a sentence without sobbing. I was a constant in their lives in a way that had me feeling humbled but also a little guilty. Had they become too dependent on me? In many cases embraced by generations of families, I was now caring for the children of the children who had seen me as babies. Incremental primary care, so aptly described by Atul Gawande, ${ }^{6}$ creates a rich scaffolding, extraordinarily intimate and imbued with years of shared experience. It was a loss, and acknowledging the grief that accompanies this loss was a crucial discussion.

There were a very few who greeted my departure with a shrug and barely a thank you - a disconnect between my own perception of my value and that of the patient. Perhaps my tone, my haste or too much staring at the computer gave them the wrong message. There were those who reminded me doctors are in a service industry. "Who will fill out my forms and answer my emails?" were the first words they uttered.

Many were excited for me. Quite a few asked if we could be friends. One of the more surprising overtures came from a hip 27-year-old, who blurted, "Great - can we hang out?" Although these gestures were uttered with genuine conviction, they would likely not materialize once my caregiver role was finished.

Saying good-bye, like delivering care, has been an incremental process. There are some, like Corinne, with whom I will stay in touch. Although no longer her medical advisor, I remain a witness to her strength and resilience.

Inevitably I will cross paths with some patients. They may remind me of pivotal moments in their lives when my practice provided a place of safety. Long past good- bye, I will be grateful they let me in, helped me mature as their doctor and left me humbled by their heroism. I am better for having known them.

\section{Pauline Pariser MD MASc}

University Health Network; Department of Family and Community Medicine, University of Toronto, Toronto, Ont.

\section{References}

1. How to retire guide. Vancouver: Divisions of Family Practice; 2016. Available: www.divisionsbc. $\mathrm{ca} /$ provincial/what-we-do/physician-support/ retirement (accessed 2019 Feb. 10).

2. Collier R. Diagnosing the aging physician. CMAJ 2008;178:1121-3.

3. Silver MP, Hamilton AD, Biswas A, et al. A systematic review of physician retirement planning. Hum Resour Health 2016;14:67.

4. Petterson SM, Rayburn WF, Liaw WR. When do primary care physicians retire? Implications for workforce projections. Ann Fam Med 2016;14:344-9.

5. Transition out of practice: a guide for physicians. Toronto: HealthForceOntario; 2016. Available: www.healthforceontario.ca/UserFiles/file/ToPS/ TransitionOutOfPractice-en.pdf (accessed 2018 Aug. 5).

6. Gawande A. "The heroism of incremental care." The New Yorker 2017 Jan. 23. Available: www.new yorker.com/magazine/2017/01/23/the-heroism-of -incremental-care (accessed 2017 Sept. 1).

This article has been peer reviewed.

This is a true story. Corinne has given her consent for this story to be told. Her name has been changed. 